\title{
Injuries in Short Track Speed Skating
}

\author{
Kolenc $\mathbf{M}^{*}$ \\ Faculty of Kinesiology, University of Zagreb, Croatia
}

ISSN: 2577-1914

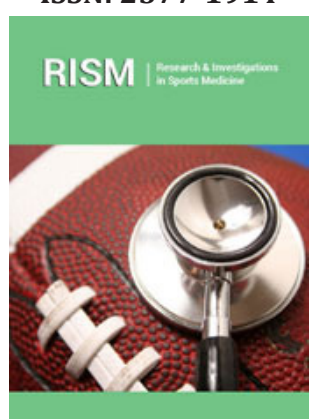

*Corresponding author: Kolenc M, Faculty of Kinesiology, University of Zagreb Croatia

Submission: 此 October 01, 2019

Published: 侮 December 17, 2019

Volume 5 - Issue 5

How to cite this article: Kolenc M. Injuries in Short Track Speed Skating. Res Inves Sports Med. 5(5). RISM.000625.2019. DOI: 10.31031/RISM.2019.05.000625

Copyright@ Kolenc M, This article is distributed under the terms of the Creative Commons Attribution 4.0 International License, which permits unrestricted use and redistribution provided that the original author and source are credited.

\begin{abstract}
Short track speed skating is an Olympic sport that has been on olympic programme since 1992. During competitive season $64.2 \%$ of professional skaters sustain at least one injury and they are equally distributed through training and competition. As in every other sport, injuries are a part of training and competition process. Most common injuries are the injuries regarding lower extremities, such as: knee contusion, muscle starins, fractures and sprains. When disscusing about injuries in short track, one must take into account four different ascpects: racing style, sport equipment, rink size and skating postition. All of these aspects have a certain role in increasing the posibility for injury. Explosive knee valgus, internal rotation od the knee and high front tibial shear force, which are main movements in short track, are the movements that will most likely lead to an ACL injury. There are some basic ways to prevent an injury; basic as a good warm up prior to training. It is always better to prevent than to cure.
\end{abstract}

\section{Introduction}

Short track speed skating is an Olympic sport that has been on olympic programme since 1992. It is a form of competitive ice speed skating that takes place at internationalsized hockey ice rink, where 4-8 skaters compete on a 111,12m long track across three main individual events: $500 \mathrm{~m}, 1000 \mathrm{~m}, 1500 \mathrm{~m}$. During competitive season $64.2 \%$ of professional skaters sustain at least one injury and they are equally distributed through training and competition. As in every other sport, injuries are a part of training and competition process. Causes of them can be numerous, such as: mistakes in planning and programing a training process, accidental fall during training or competition, overtraining/overreaching, wrong movement due to lack of concentration caused by fatigue, continuous high overload on joints, tendons, ligaments, etc. Most common injuries are the injuries regarding lower extremities, such as: knee contusion, muscle starins, fractures and sprains.

\section{Injuries}

When disscusing about injuries in short track, one must take into account four different ascpects: racing style, sport equipment, rink size and skating postition. In short track, as above mentioned, skaters race in groups of 4-8 people; and every single one of them wants to win. Usually, no contact should be allowed, but it is impossible to remove all of it. Due to contacts, tight corners and high speed, it is easy to fall alone or in a group, where most of injuries occur. Ice rink size adds up to possibility of injuries. Namely, when skaters fall or just "slip away" they have less than a second to come up with the best position to hit the pads; main advice is to hit the pads sideways. Sometimes, when the skater is falling alone, it is quite simple to turn around, but the problem emerges when they are falling in the group. There are more things to concetrate on, such as: hitting the pads in best position while trying to separate from other skater/skaters so there isn't any collision between skaters. Another thing that adds up to the posibility of injury is equipment that skaters use. Skaters skate on very sharp blades, and while they are wearing kevlar skin suits to protect them, cuts happen. Also, kevlar skin suits do not cover every piece of skin, so face and a part of the neck are still exposed (Figure 1).

Last aspect of short track that adds up to a posibility of an injury is skating position/ technique. Skating position i salso referred to as "crouched" position due to rounded back of the skater and low position of the hips with knees flexed around $90^{\circ}$ followed by center of pressure form the middle of the foot to the toes. Rounded back cause unnatural cruvature of the spine which leads to shortetning the lever on which back muscles must exert force 
and thus increase the distance from the point where external force is acting on the skater. It also causes the intervertebral discs to be compressed in suach way that they are pushed dorsally. While in the corner, skaters adopt a position which move spine in transversal plane, sometimes developing scoliosis in young skaters. Most of the skaters often experience low back pain followed by ischialgia due to a compression of the nerve ischiadicus by piriformis muscle $[1,2]$.
Figure 1: Skating position.

Going into a squat position while keeping the pressure on toes results in a higher tension on quadriceps tendon and patella. Also, during skating, flexion, abduction and internal rotation of the knee happen in such manner that equals the threshold of ACL injury during side stepping; which is similar to movements in short track. That, accompanied with high intramuscular forces, gives way to injury to occur. The positive side is that, in the moment when high intramuscular forces, explosive knee valgus, internal rotation and high front tibial shear force happen, the knee is in flexion; hence ligaments are not fully tense, like they are when the knee is streched.
Furthermore, more common injuries are distal tibia and fibula fracutres and smaller and bigger lacerations. Fracutres at that exact point occur the most due to a fixture of ankle in short track boot. When the ankle cannot compensate the torque that is happening while either hitting the pads feet first or accidentaly pinning the blade into the ice, that force is translated to the distal parts of the tibia and fibula and other musculoskeletal structures. Since the distal end of tibia and fibula are the closest to the ankle, they take up most of the torque and inevitably break (Figure 2).

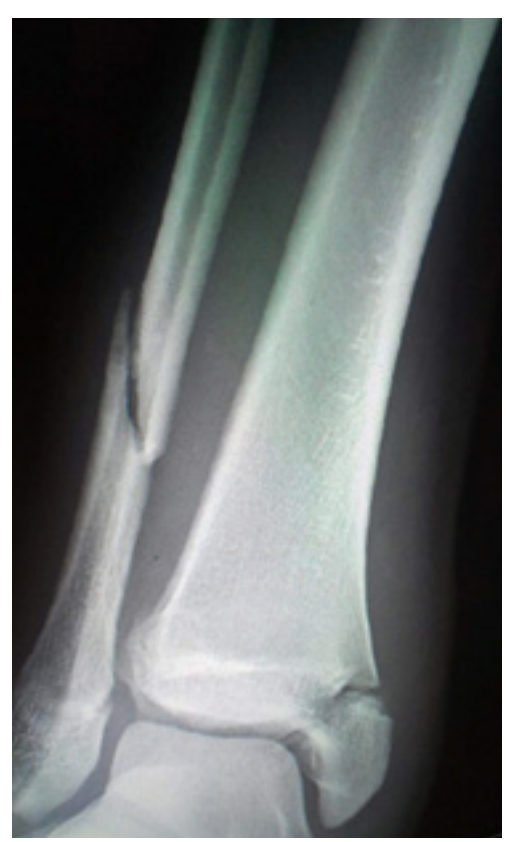

Figure 2: Fibula fracture. 


\section{Prevention}

There are some basic ways to prevent different injuries:

1. Warm up

2. Control the load throughout the training process

3. Develop technique over strenght

4. Constanly remind skaters to keep the focus on movements they perform

5. Involve exercises that allow skaters to get into the "injury" position safely, thus adapting musculoskeletal structures to ranges of motions/postitions where injury would normaly occur [3-5].

\section{Conclusion}

Injuries are an inevitable part of the sport. With every practice and competition the chance of injury increases and they are almost impossible to predict. But, with constant monitoring of athletes musculoskeletal system and psychological aspect, we can somehow help prevent the posibility for them to occur. It is better to prevent than to cure.

\section{References}

1. Quinn A, Lun V, McCall J, Overend T (2003) Injuries in short track speed skating. The American Journal of Sports Medicine 31(4): 507-510.

2. de Boer RW, Ettema GJ, van Gorkum H, de Groot G, van IngenSchenau GJ (1987) Biomechanical aspects of push-off techniques in speed skating the curves. Int J Sport Biomech 3(1): 69-79.

3. de Koning JJ, de Groot G, van IngenSchenau GJ (1989) Mechanical aspects of the sprint start in olympic speed skating. Int J Sport Biomech 5(2): 151-168.

4. Purevsuren T, Batbayar Khuyagbaatar, Kyungsoo Kim, Yoon Hyuk Kim (2018) Investigation of knee joint forces and moments during shorttrack speed skating using wearable motion analysis system. Int J Pr Eng Mangt 19(7): 1055-1060.

5. Shin CS, Chaudhari AM, Andriacchi TP (2011) Valgus plus internal rotation moments increase anterior cruciate ligament strain more than either alone. Med Sci Sports Exerc 43(8): 1484-1491. 